\title{
CATION-DIFFUSION-INDUCED CHARACTERISTIC BEAM DAMAGE IN TRANSMISSION ELECTRON MICROSCOPE IMAGES OF MICAS *
}

\author{
Jung Ho AHN, Donald R. PEACOR and Eric J. ESSENE \\ Department of Geological Sciences, The University of Michigan, Ann Arbor, Michigan 48109, USA
}

Received 15 April 1986

\begin{abstract}
Transmission and analytical electron microscopy have been used to characterize the numerous lenticular fissures which were observed in electron micrographs of paragonite. Observations with a very weak electron beam revealed that there were no fissures in the original paragonite and that the degree of damage is a function of exposure to the beam. AEM analysis revealed that there is significant loss of $\mathrm{Na}$ in the beam-damaged paragonite. The fissures may be caused by collapse of the paragonite structure to a pyrophyllite-like structure, which has a smaller basal spacing due to loss of interlayer Na. Data from a survey of TEM observations of other phyllosilicates which show similar features imply that the fissures are directly associated with the interlayer cation $\mathrm{Na}$ and that beam damage effects are related to the interlayer cations in micas.
\end{abstract}

\section{Introduction}

The interaction of the high energy electron beam with a specimen results in inelastic scattering with various energy transfer processes, including permanent atomic displacements, which are referred to as "beam damage" or "radiation damage". Beam damage is a serious problem, especially in organic or biological materials [1-4], but is also significant and has been studied extensively in inorganic solids $[5,6]$.

Transmission electron microscopy (TEM) and analytical electron microscopy (AEM) are more frequently being used in studies of phyllosilicates, and these techniques have contributed much to our understanding of the microstructure and microchemistry of these minerals, even though phyllosilicates are known to be very sensitive to electron beam irradiation [7-13]. However, there are few detailed studies of the effects of beam damage on phyllosilicates, which, if present, may result in features due to beam damage being misinterpreted or direct observation of primary structures being hindered. In this paper we describe a detailed

\footnotetext{
* Contribution No. 426, The Mineralogical Laboratory, Department of Geological Sciences, The University of Michigan, Ann Arbor, Michigan 48109, USA.
}

study of beam damage effects in sodium micas, especially paragonite, and we review related beam damage features in other micas as well as phyllosilicates in general.

\section{Specimens and experimental methods}

The specimen used in this study is from a gneissic blueschist eclogite (University of California, Berkeley, No. 665-C19) from the Franciscan Formation at Cazadero, California, previously characterized by Essene [14]. Coexisting paragonite and phengite in this specimen were studied by Ahn et al. [15] using TEM and electron microprobe observations.

Ion-thinned samples were examined at $100 \mathrm{kV}$ in a JEOL JEM-100 CX scanning transmission electron microscope (STEM) fitted with a solid state detector for $\mathrm{X}$-ray energy dispersive analysis and modified for AEM by Blake et al. [16] and Allard and Blake [17]. Sample preparation and experimental techniques used in this study were described by Ahn et al. [15].

\section{Electron microscopic observations}

Electron micrographs show that both paragonite and phengite have a very similar appearance. 


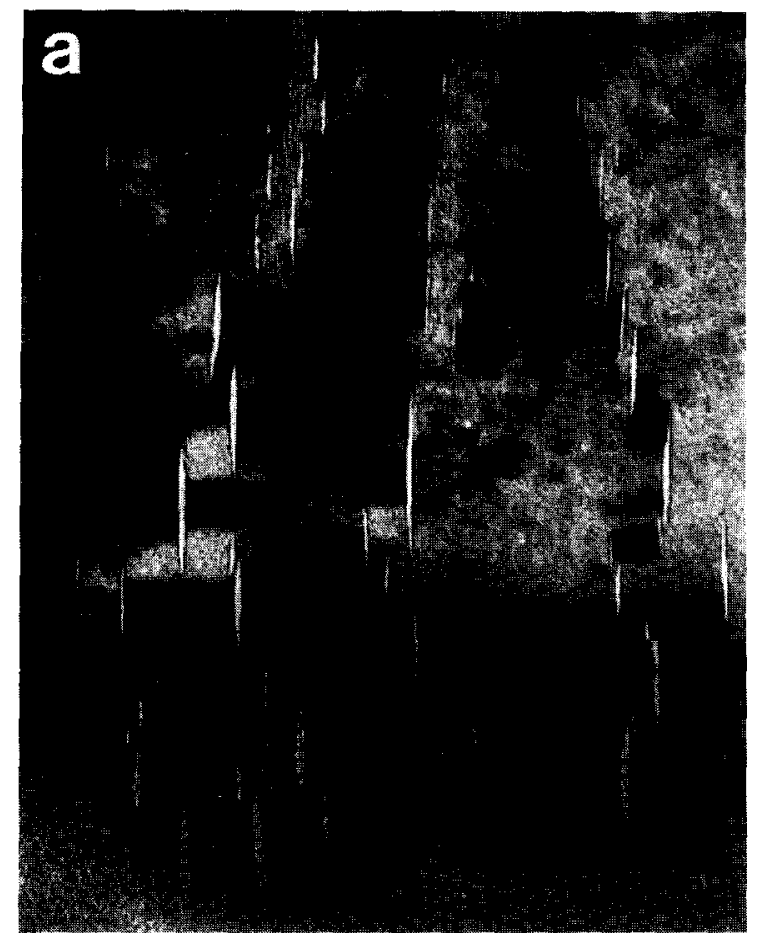

b

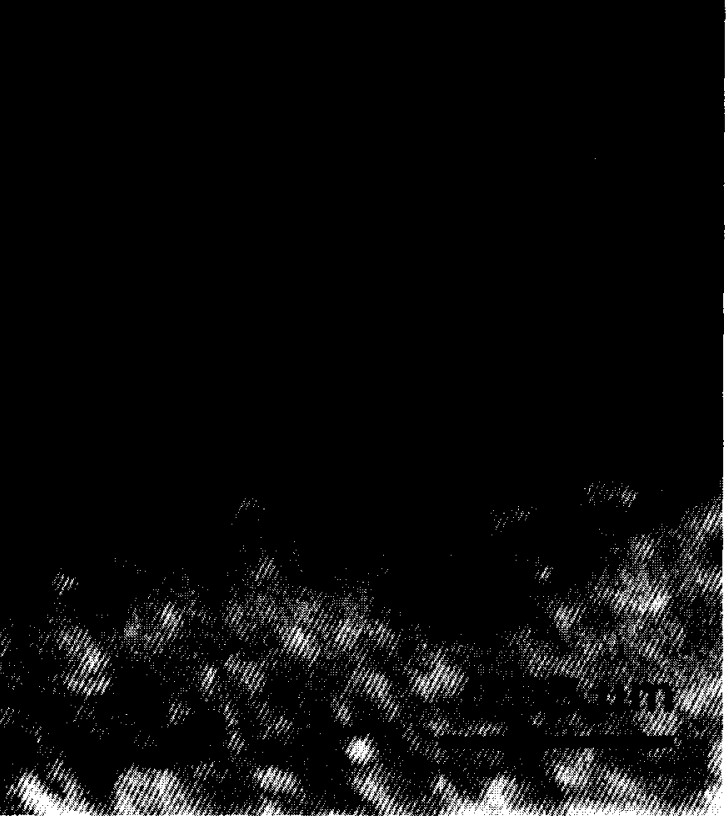

Fig. 1. Low magnification TEM electron micrographs of typical paragonite (a) and phengite (b).
They show a "mottled texture" which is commonly observed in micas [18-20] (figs. 1a and b). The only difference in appearance between these two micas is the presence of lenticular fissures in
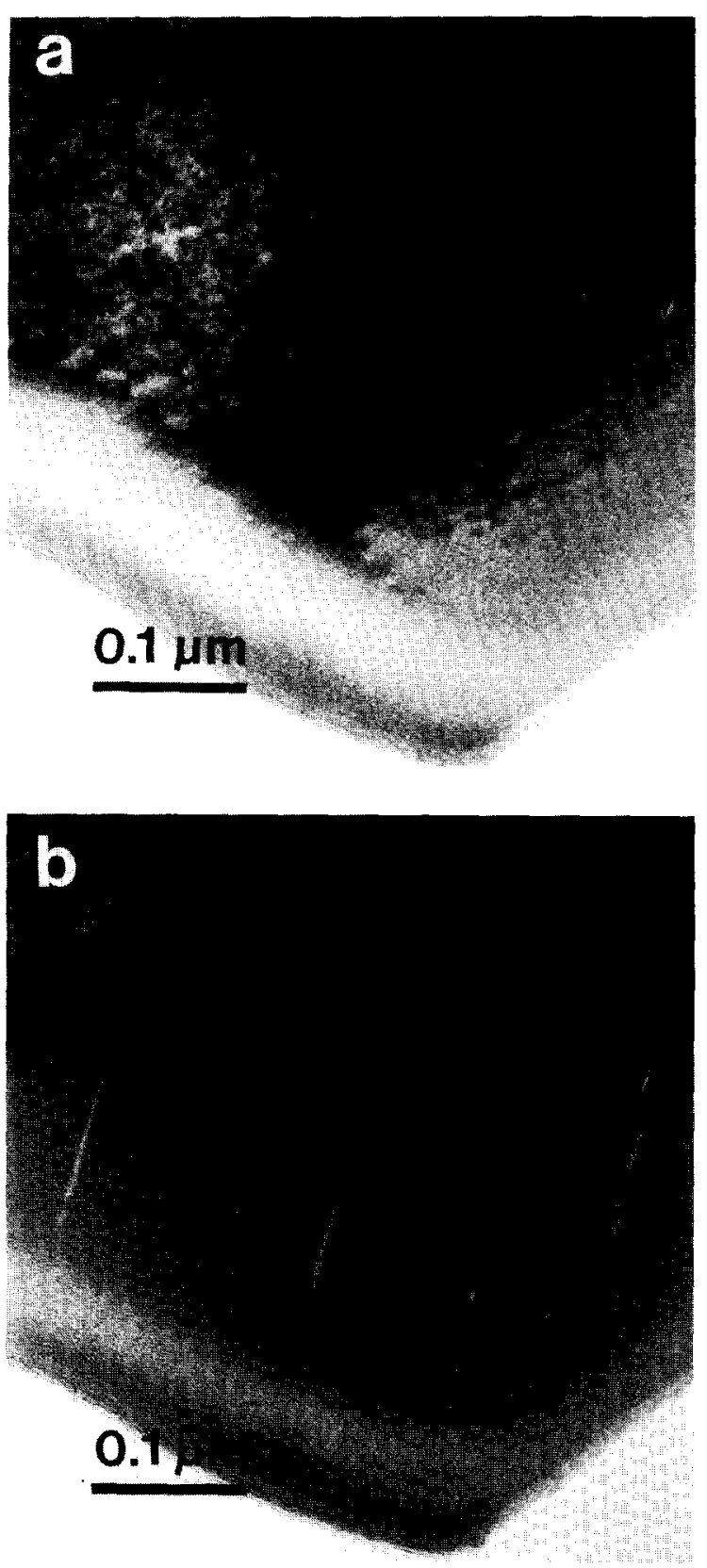

Fig. 2. Low magnification TEM electron micrographs of paragonite with minimum electron beam irradiation (a) and same area with an additional $10 \mathrm{~s}$ electron beam irradiation $(\mathrm{b})$. 
paragonite (fig. 1a). Phengite does not show this feature (fig. 1b). Similar lenticular fissures in phyllosilicates have been described by many authors $[11,12,18,21,22]$.

We observed paragonite with minimum electron beam exposure at low magnification in order to minimize possible beam damage effects and to determine if the fissures are an original microstructure of paragonite or are caused by beam damage. Such exposure produced an image without any prominent fissures (fig. 2a). Subsequently, the same area was exposed to a high intensity electron beam for an additional $10 \mathrm{~s}$ and another electron micrograph was obtained (fig. 2b). It shows abundant fissures which appear at thin edges. Those fissures are elongated perpendicular to $c^{*}$. Quantitative AEM analyses confirmed that this area consists of paragonite with no other intergrown phases. We attempted to obtain high magnification lattice fringe images of undamaged parago- nite, but every image exhibited the characteristic fissures (fig. 3) because the much higher electron beam intensity required for this purpose is sufficient to cause the damage. The 001 layers are apparently continuous but deflected around the fissures. The size of fissures varies from being barely observable to almost $100 \AA$ in width. These combined observations confirm that the fissures are not a primary microstructure but a secondary feature caused by electron damage.

In addition, an electron diffraction pattern from an area previously unexposed to the electron beam shows sharp reflections (fig. $4 \mathrm{a}$ ), while that from a beam-damaged area gives rise to a more diffuse electron diffraction pattern (fig. 4b). Reflections are diffuse both parallel and perpendicular to $c^{*}$. The diffuseness perpendicular to $c^{*}$ in each reflection is caused by misorientation of split lamellae, because lenticular partings along the layers cause a small degree of rotation of paragonite lamellae

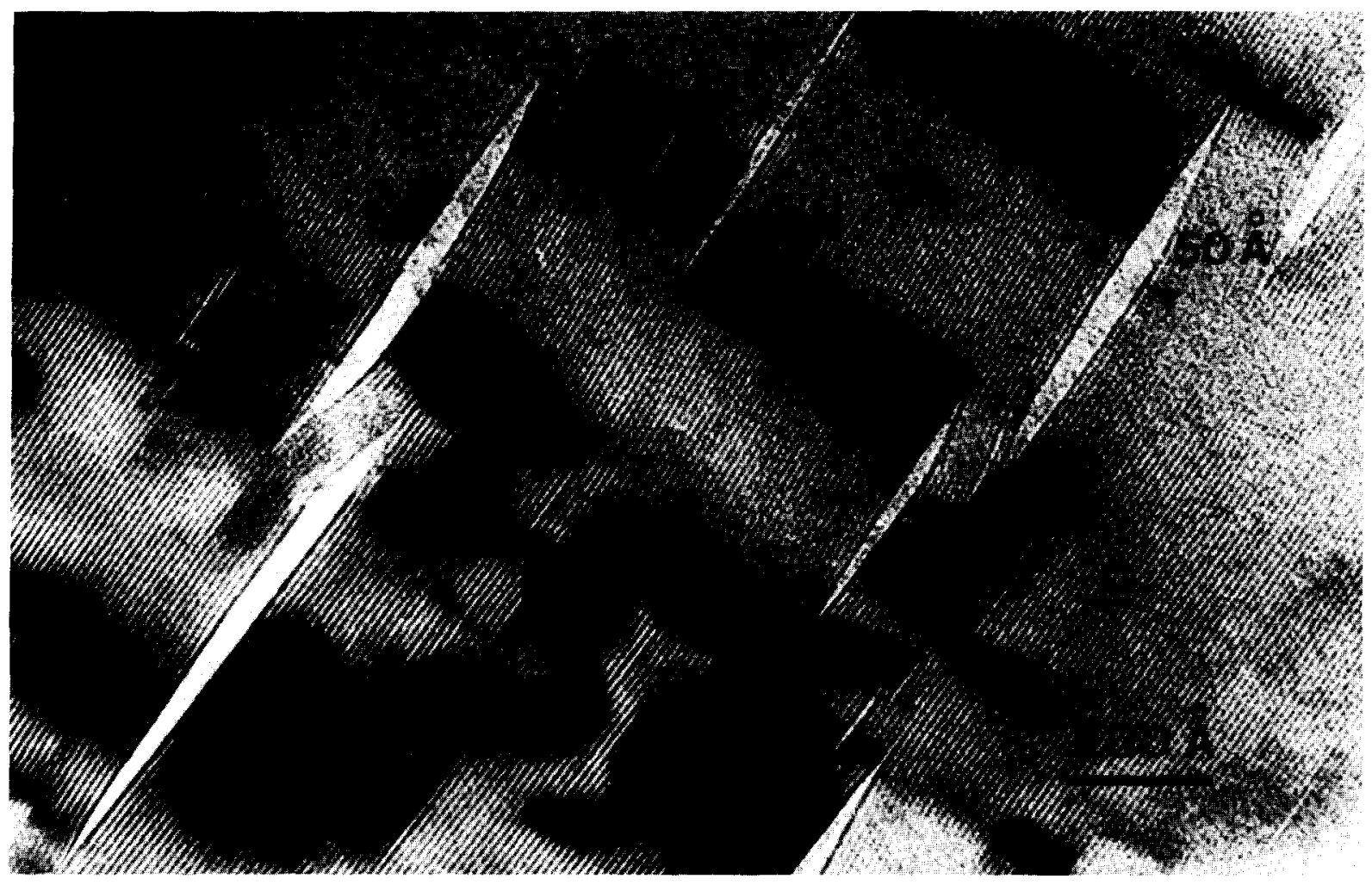

Fig. 3. Lattice fringe image of beam-damaged paragonite showing lenticular layer separations along layers. 

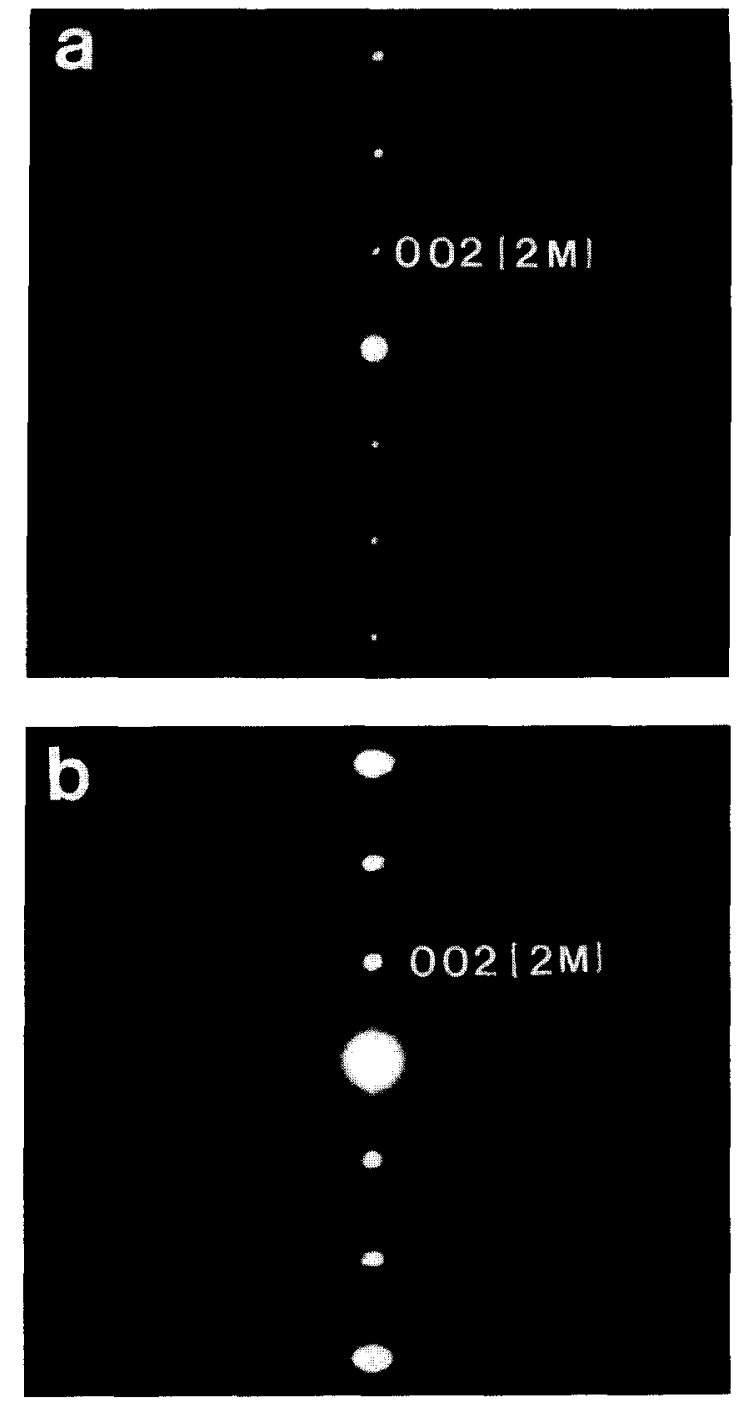

Fig. 4. (a) An electron diffraction pattern of paragonite previously unexposed to electron beam showing sharp reflections and (b) an electron diffraction pattern of beam-damaged paragonite showing diffuse reflections.

around $c^{*}$ (fig. 3). The diffuseness along $c^{*}$ indicates that there has been some change or variation in basal spacing; i.e., the structure and/or chemistry of some layers have been affected by electron beam irradiation. However, lattice fringes bordering the fissures are still clearly observable, implying that the basic paragonite structure near the fissure has been unchanged during the formation of the fissures.
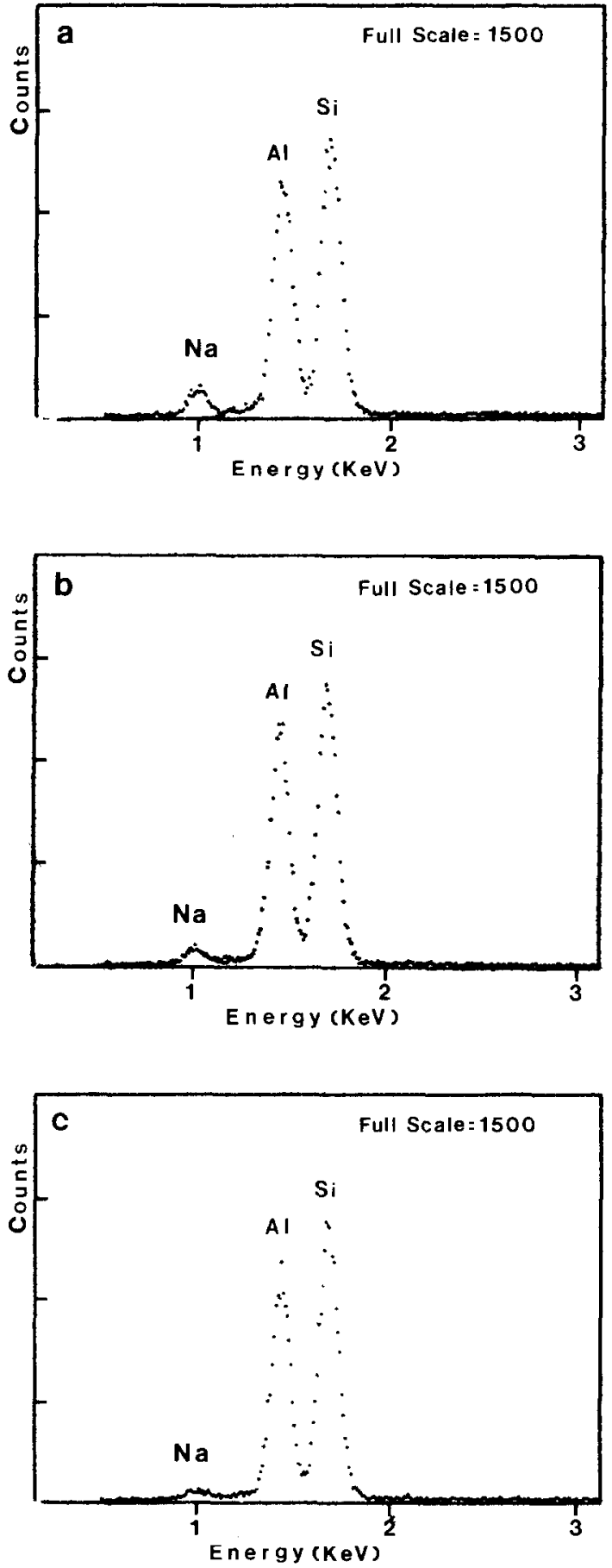

Fig. 5. Energy dispersive X-ray spectra of the paragonite before electron beam exposure (a), after $100 \mathrm{~s}$ exposure to the electron beam (b), and after $200 \mathrm{~s}$ exposure to the electron beam $(\mathrm{c})$. 
Paragonite grains were analyzed semiquantitatively by using AEM techniques in order to determine if there is any chemical change caused by beam damage. An X-ray spectrum was obtained from paragonite which was previously unexposed to the electron beam (fig. 5a); X-ray spectra were subsequently obtained every $100 \mathrm{~s}$ from the same area (figs. $5 \mathrm{~b}$ and $5 \mathrm{c}$ ). Care was taken to prevent specimen drift during analyses so that the serial analyses are from the same area. The results clearly show that there is no significant variation in $\mathrm{Al}$ and $\mathrm{Si}$, while the height of the $\mathrm{Na}$ peak gradually decreases with increasing electron beam irradiation.

\section{Origins of layer separations in paragonite}

Because AEM data show that there is a considerable decrease in $\mathrm{Na}$ content relative to $\mathrm{Al}$ and $\mathrm{Si}$ with electron beam irradiation, the fissures are inferred to be related to loss of $\mathrm{Na}$. Beam-induced loss of light elements is a well known phenomenon [2-4,23]. In addition, loss of $\mathrm{Na}$ in plagioclase is reported during electron microprohe analysis (e.g., ref. [24]) and this is routinely taken into account in analytical procedures not only for plagioclase, but for many other minerals. In phyllosilicates the rate of cation diffusion is thought to be much greater parallel to layers than normal to layers [21]. Na can therefore easily diffuse or be volatilized from the thin edges of samples, because specimens are prepared so that the layers are parallel to the incident beam direction and normal to the plane of the thin edge.

Loss of $\mathrm{Na}$ from paragonite must eventually cause collapse of the paragonite structure to a pyrophyllite-like structure (which has no interlayer cations), causing volume loss and, therefore, reduction of the basal spacing. Release of the resulting elastic strain associated with the local collapse may cause mechanical separation of paragonite layers along (001). Bonding between layers along interlayer sites is much weaker than that across tetrahedral and octahedral layers and the fissures are therefore inferred to occur along the interlayers. Propagation of the fissures, therefore, will occur parallel to (001).
The basal spacing of ideal pyrophyllite is approximately $9.3 \AA$ and that of paragonite is $9.6 \AA$. The width of the layer separation parallel to $c^{*}$ should therefore be approximately $3 \%$ of the entire region, assuming that all of the paragonite collapses to a pyrophyllite-like structure. However, the measured width of the fissures is approximately $6 \%$ of the entire paragonite area along $c^{*}$. Therefore, the width of the fissure is still only partly accounted for, even though paragonite might lose all interlayer $\mathrm{Na}$ and collapse completely to a pyropyllite-like structure.

Other kinds of disruption or collapse of the paragonite structure by beam damage are more speculative. However, Iijima and Zhu [11] observed that biotite and muscovite become noncrystalline with further electron beam irradiation. In micas this may be due to structural deformation involving bond rupture between tetrahedral and octahedral layers by loss of $\mathrm{OH}$ [11]. If there is further structural deformation in the mica structure, the layer width will decrease further from that of a collapsed pyrophyllite-like structure, and this may provide some explanation for the width of the fissures in paragonite.

\section{Layer separations in other phyllosilicates}

Schreyer et al. [12] carried out a TEM study of kulkeite, which has an ordered 1:1 chlorite/talc mixed-layer structure. The talc layers in kulkeite have some $\mathrm{Na}$ in the interlayer which is chargebalanced by Al substitution for Si. TEM micrographs of kulkeite exhibit lenticular fissures that appear to be identical to those of paragonite (e.g., figs. $1 \mathrm{a}$ and 3 ). These features were interpreted as some kind of original structural defect (figs. 6 and 9 in Schreyer et al. [12]). In addition, wider lenticular fissures with a similar appearance were observed by Veblen $[18,21]$ in TEM observations of wonesite. The chemistry of the interlayer sites of wonesite is $\mathrm{Na}_{0.40} \mathrm{~K}_{0.07} \square_{0.53}$. Paragonite, kulkeite, and wonesite all exhibit characteristic lenticular voids and are all $\mathrm{Na}$ micas or contain limited $\mathrm{Na}$ as an interlayer cation. The occurrence of the lenticular fissures therefore appears to be common in micas which contain sodium in interlayer sites. 
However, similar fissures occurring in $\mathrm{K}$ micas have been reported by several investigators. For example, Iijima and Zhu [11] observed rare fissures in biotite and muscovite, and they suggested that they formed during sample preparation. In addition, Olives et al. [22] observed similar splitting of biotite layers and interpreted that as an original microcleavage. However, fissures observed in biotite and muscovite are rare and are not as prominent and abundant as those in paragonite or other $\mathrm{Na}$-containing phases.

Page [19] observed strain contrast effects along layers of various phyllosilicates and related the effect to GP (Guinier-Preston) zones, adapting the term commonly applied to metal alloys. He suggested that the contrast is due to strain caused by chemical heterogeneity along layers (or to the occurrence of partial interlayers of different composition). His images do not show the obvious layer separations occurring in paragonite, but they are very similar in appearance to thick areas of damaged paragonite. Fissures vary in size from very small (similar to the textures observed by Page) to large ones almost $100 \AA$ in width (fig. 3). In addition, tiny fissures are concentrated in the thicker areas and large fissures along the thin edges (figs. $1 b$ and $2 b$ ). The differences in fissure size may be related to diffusion rates varying in areas of different thickness or to greater resistance to strain in thick areas. The "mottled texture" appears only in the thick areas and correlates with numerous tiny fissures, implying that it is a stress-induced feature casued by the numerous tiny fissures formed by beam damage effects. Such a mottled texture is characteristic of illite, and it is considered to be related to beam damage effects associated with diffusion of the interlayer cation $\mathrm{K}$ [20]. The mottled texture therefore appears to be a stress-induced effect related to the cause of the fissures in paragonite, but to a less significant degree, perhaps due to different diffusion rates for $\mathrm{K}$ and $\mathrm{Na}$.

\section{Cause of beam damage effects in micas}

The variable sensitivity of micas to electron beam irradiation has been discussed by several investigators. Veblen and Buseck [8] observed that the rate of beam damage in pyroxenes, amphiboles, biopyriboles and talc increases with increasing chain width, implying that phyllosilicates are more easily beam-damaged than chain silicates. On the other hand, Iijima and Zhu [11] suggest that the resistance of phyllosilicates to beam damage is determined by $\mathrm{OH}$ content. They observed that biotite is more stable than muscovite under electron beam exposure, and they inferred that a smaller $\mathrm{OH}$ content in biotite through substitution of $\mathrm{F}$ for $\mathrm{OH}$ caused biotite to be more resistant to beam damage than muscovite. They also inferred that the high content of $\mathrm{Fe}$, which has a higher ionization potential than $\mathrm{Al}$, also contributed to the resistance of biotite to electron beam irradiation.

However, the rapid beam damage and constant occurrence of lenticular fissures in various $\mathrm{Na}$ micas indicate that the type of interlayer cation is most important in determining beam damage effects in micas. Prominent fissures were not reported in illite and muscovite having $\mathbf{K}$ as a major interlayer cation, although they have the typical mottled texture [20]. In addition, phlogopite $\left(\mathrm{KMg}_{3} \mathrm{Si}_{3} \mathrm{AlO}_{10}(\mathrm{OH})_{2}\right)$ and margarite $\left(\mathrm{CaAl}_{2}\right.$ $\mathrm{Si}_{2} \mathrm{Al}_{2} \mathrm{O}_{10}(\mathrm{OH})_{2}$ ) were shown to be relatively stable under electron beam irradiation, and neither mica shows any layer separation [25]. The susceptibility of $\mathrm{Na}$ micas to beam damage relative to micas with other interlayer cations may thus be caused by higher mobility of $\mathrm{Na}$ compared to $\mathrm{K}$ or $\mathrm{Ca}$ in interlayer sites. Although more data should be accumulated to compare the relative resistance of various micas to electron beam irradiation as a function of the type of interlayer cation, $\mathrm{Na}$ micas are very unstable relative $10 \mathrm{~K}$ micas under electron beam exposure and show a characteristic layer separation feature.

\section{Conclusions}

The numerous lenticular fissures observed in paragonite are not a primary microstructure but are a characteristic secondary feature caused by electron beam damage. The full range of causes of such lenticular fissures is still not clear. However, 
AEM analyses indicate that there is significant loss of interlayer $\mathrm{Na}$ with electron beam irradiation of the sample, implying that collapse of the paragonite structure may be a major cause of the lenticular fissures. We conclude that the numerous lenticular fissures are a characteristic beamdamage feature of Na-containing micas, and that the species of alkali cations in interlayer sites may be important in determining the rate of beam damage. In addition, diffusion or loss of alkali cations due to beam damage of micas is a significant effect which may give rise to serious errors in AEM analyses.

\section{Acknowledgments}

We thank Dr. W.C. Bigelow and the staff of the University of Michigan Electron Microbeam Analysis Laboratory for their help with the STEM. We also thank Drs. D.R. Veblen, B.H. Wilkinson and B.A. van der Pluijm for their valuable comments on an early version of the manuscript. We are grateful to Dr. J.H. Lee and Ms. Y.C. Yau for their data. This study was supported by NSF grant EAR-83-13236 to D.R. Peacor, and the analytical scanning transmission electron microscope used in this study was acquired under NSF grant DMR-77-09643.

\section{References}

[1] K.S. Stenn and C.F. Bahr, J. Ultrastruct. Res. 31 (1970) 526.

[2] K.S. Stenn and C.F. Bahr, J. Histochem. Cytochem. 18 (1970) 574.

[3] Y.A. Hall and B.L. Gupta, in: Introduction to Analytical Electron Microscopy, Eds. J.J. Hren, J.I. Goldstein and
D.C. Joy (Plenum, New York, 1979) p. 169.

[4] R.M. Glaeser, in: Introduction to Analytical Electron Microscopy, Eds. J.J. Hren. J.I. Goldstein and D.C. Joy (Plenum, New York, 1979) p. 423.

[5] L.W. Hobbs, Ultramicroscopy 3 (1979) 381.

[6] L.W. Hobbs, in: Introduction to Analytical Electron Microscopy, Eds. J.J. Hren, J.I. Goldstein and D.C. Joy (Plenum, New York, 1979) p. 437.

[7] I.A. Bell and C.J.L. Wilson. Tectonophysics 78 (1081) 201.

[8] D.R. Veblen and P.R. Buseck, Am. Mineralogist 64 (1979) 687.

[9] D.R. Veblen and P.R. Buseck. Am. Mineralogist 65 (1980) 599.

[10] D.R. Veblen and P.R. Buseck, in: Proc. 41st Annual EMSA Meeting. Phoenix, AZ, 1983, Ed. G.W. Bailey (San Francisco Press, San Francisco, 1984) p. 350.

[11] S. Iijima and J. Zhu, Am. Mineralogist 67 (1982) 1195.

[12] W. Schreyer, O. Medenbach, K. Abraham, W. Gerbert and W.F. Müller. Contrib. Mineral. Petrol. 80 (1982) 103.

[13] G.E. Spinnler, P.G. Self, S. Iijima and P.R. Buseck. Am. Mineralogist 69 (1984) 252.

[14] E.J. Essene, HhD Ihesis, University of California, Berkeley (1967).

[15] J.H. Ahn, D.R. Peacor and E.J. Essene. Am. Mineralogist 70 (1985) 1193.

[16] D.F. Blake, L.F. Allard, D.R. Peacor and W.C. Bigelow, in: Proc. 38th Annual EMSA Meeting. San Francisco. 1980, Ed. G.W. Bailey (Claitor's. Baton Rouge, LA. 1980) p. 136.

[17] L.F. Allard and D.F. Blake, in: Proc. 17th Conf. Microbeam Analysis Society, 1982, p. 8.

[18] D.R. Veblen, Am. Mineralogist 68 (1983) 566.

[19] R.H. Page, Contrib. Mineral. Petrol. 75 (1980) 309.

[20] J.H. Lee, D.R. Peacor, D.D. Lewis and R.P. Wintsch. Contrib. Mineral. Petrol. 88 (1984) 372.

[21] D.R. Veblen, Am. Mineralogist 68 (1983) 554.

[22] B.J. Olives, M. Amouric. C. de Fouquet and A. Baronnet, Am. Mineralogist 68 (1983) 754.

[23] J. Wall, in: Introduction to Analytical Electron Microscopy, Eds. J.J. Hren, I.I. Goldstein and D.C. Joy (Plenum. New York, 1979) p. 333.

[24] P.H. Ribbe and J.V. Smith, J. Geol. 74 (1966) 217.

[25] Y.C. Yau, L.M. Anovitz, E.J. Essene and D.R. Peacor, Contrib. Mineral. Petrol. 88 (1984) 299. 